\title{
Article \\ HPE1, an Effector from Zebra Chip Pathogen Interacts with Tomato Proteins and Perturbs Ubiquitinated Protein Accumulation
}

\author{
Chia-Cheng Kan ${ }^{1}{ }^{\oplus}$, Azucena Mendoza-Herrera ${ }^{1}$, Julien Levy ${ }^{2}{ }^{\oplus}$, J. Joe Hull ${ }^{3} \oplus$, Jeffery A. Fabrick ${ }^{3}$ \\ and Cecilia Tamborindeguy ${ }^{1, *}$
}

1 Department of Entomology, Texas A\&M University, College Station, TX 77843, USA; cckan@tamu.edu (C.-C.K.); azucena.mendoza@tamu.edu (A.M.-H.)

2 Department of Horticultural Sciences, Texas A\&M University, College Station, TX 77843, USA; julienlevy@tamu.edu

3 USDA-ARS, Arid Land Agricultural Research Center, Maricopa, AZ 85138, USA; joe.hull@usda.gov (J.J.H.); jeff.fabrick@usda.gov (J.A.F.)

* Correspondence: ctamborindeguy@tamu.edu

\section{check for} updates

Citation: Kan, C.-C.; MendozaHerrera, A.; Levy, J.; Hull, J.J.; Fabrick, J.A.; Tamborindeguy, C. HPE1, an Effector from Zebra Chip Pathogen Interacts with Tomato Proteins and Perturbs Ubiquitinated Protein Accumulation. Int. J. Mol. Sci. 2021, 22, 9003. https://doi.org/10.3390/ ijms22169003

Academic Editors: Hang Thi Thu Nguyen and Kenji Miura

Received: 13 July 2021

Accepted: 16 August 2021

Published: 20 August 2021

Publisher's Note: MDPI stays neutral with regard to jurisdictional claims in published maps and institutional affiliations.

Copyright: (c) 2021 by the authors. Licensee MDPI, Basel, Switzerland. This article is an open access article distributed under the terms and conditions of the Creative Commons Attribution (CC BY) license (https:// creativecommons.org/licenses/by/ $4.0 /)$.

\begin{abstract}
The gram-negative bacterial genus Liberibacter includes economically important pathogens, such as 'Candidatus Liberibacter asiaticus' that cause citrus greening disease (or Huanglongbing, HLB) and 'Ca. Liberibacter solanacearum' (Lso) that cause zebra chip disease in potato. Liberibacter pathogens are fastidious bacteria transmitted by psyllids. Pathogen manipulation of the host' and vector's immune system for successful colonization is hypothesized to be achieved by Sec translocondependent effectors (SDE). In previous work, we identified hypothetical protein effector 1 (HPE1), an SDE from Lso, that acts as a suppressor of the plant's effector-triggered immunity (ETI)-like response. In this study, using a yeast two-hybrid system, we identify binding interactions between tomato RAD23 proteins and HPE1. We further show that HPE1 interacts with RAD23 in both nuclear and cytoplasmic compartments in planta. Immunoblot assays show that HPE1 is not ubiquitinated in the plant cell, but rather the expression of HPE1 induced the accumulation of other ubiquitinated proteins. A similar accumulation of ubiquitinated proteins is also observed in Lso infected tomato plants. Finally, earlier colonization and symptom development following Lso haplotype B infection are observed in HPE1 overexpressing plants compared to wild-type plants. Overall, our results suggest that HPE1 plays a role in virulence in Lso pathogenesis, possibly by perturbing the ubiquitinproteasome system via direct interaction with the ubiquitin-like domain of RAD23 proteins.
\end{abstract}

Keywords: Ca. Liberibacter solanacearum; effector; HPE1; ubiquitin-proteasome system; RAD23

\section{Introduction}

The bacterial genus Liberibacter includes several economically important pathogens, such as 'Candidatus Liberibacter asiaticus' (Las), 'Ca. L. americanus', and 'Ca. L. africanus' that cause citrus greening disease (or Huanglongbing, HLB), as well as 'Ca. L. solanacearum' (Lso), the causal agent of Zebra chip disease in potato and other diseases. At least seven Lso haplotypes have been reported globally based on different host-vector systems [1]. In the Americas, LsoA and LsoB are vectored by the potato psyllid (also known as tomato psyllid), Bactericera cockerelli (Šulc) (Hemiptera: Triozidae) [2,3], and infect solanaceous species.

Liberibacter pathogens are phloem-limited, obligate parasitic bacteria. They are transmitted by psyllids, which are phloem-feeding insects, in a persistent propagative manner [4,5]. Manipulations of the metabolism and immune response by these pathogens have been reported in the infected plant hosts, and insect vectors through multi-omic approaches in the past decade. In response to infection, both Las- and Lso-infected host plants undergo shifts in carbohydrate metabolism, and downregulation of photosynthesis- 
and defense-related genes [6-9]. On the other hand, in response to Liberibacter infections, psyllid vectors show dramatic changes in the expression of genes involved in the citric acid cycle, stress-resistance, and the immune system $[10,11]$. How these pathogens with simple genomes $(\sim 1.2 \mathrm{Mb})$ manipulate their plant hosts and insect vectors remains unclear.

Accumulating evidence suggests that pathogens use secreted proteins (effectors) to overcome the host immune response and manipulate the host cellular functions to their own benefit. For example, Pseudomonas syringae pv tomato DC3000 (Pst) effector AvrPtoB was the first E3 ubiquitin ligase-like effector reported to suppress programmed cell death in plants [12]. RipAW and RipAR from Ralstonia solanacearum suppress patterntriggered immunity (PTI) in plants, especially the production of reactive oxygen species, and downregulate the expression of PTI marker genes [13]. Effectors, such as HopBB1 from Pseudomonas syringae and HaRxL44 from Hyaloperonospora arabidopsidis, use different mechanisms to disturb the ubiquitin/26S proteasome system (UPS), probably by acting as adaptors between the substrates and E3 ligases, resulting in the alteration of phytohormonerelated gene transcription and manipulation of plant defenses [14,15].

Unlike the above-mentioned extracellular prokaryotic pathogens, intracellular pathogens, such as Ca. phytoplasma and Liberibacter, do not encode syringe-like secretion systems (type III, type IV, and type VI) dedicated for delivering effectors to host cells. Instead, secretion systems utilizing the general secretory (SEC) or twin-arginine translocation (Tat) pathways are assumed to take dominant roles for delivering virulence proteins to their destinations. Phytoplasma effector SAP54 was one of the first reported Sec-dependent effectors of this kind [16]. SAP54 interacts with Arabidopsis thaliana flowering related MADSbox transcription factors and the RADIATION SENSITIVE23 (RAD23) family proteins, RAD23c and RAD23d, to mediate the phyllody symptom [17]. SAP54 may play a role as an indirect adaptor regulating the degradation of MADS-box proteins, which represents a new mechanism used by pathogens to perturb proteostasis via the $26 \mathrm{~S}$ proteasome [18].

To identify potential Liberibacter effectors, SEC translocon-dependent secreted proteins were predicted from the Las and Lso genomes by bioinformatic analyses [19-21]. The involvement of some of these predicted effectors in plant infection has been determined. For example, SDE1 (CLIBASIA_05315) is more highly expressed when the bacterium is in citrus rather than when present in the psyllid vector. It was determined that SDE1 interacts with members of papain-like cysteine proteases (PLCPs) by yeast two-hybrid (Y2H), and that it inhibits PLCP activity in vitro [22]. CLIBASIA_00460 is also a Sec-dependent protein that is highly expressed in citrus. Heterologous expression of CLIBASIA_00460 in Nicotiana benthamiana leads to local and systemic necrosis [23]. Identified by similar approaches, CLIBASIA_00470, CLIBASIA_040250, CLIBASIA_04065c, and CLIBASIA_05150 cause strong cell death symptoms at the systemic leaves in tobacco, and their potential interactors in the host plant were identified by $\mathrm{Y} 2 \mathrm{H}$ screening. Understanding the function of Las and Lso Sec translocon-dependent effectors is critical to understand how these intracellular plant pathogens colonize host plants.

In addition to the above-mentioned function of virulence factors, Liberibacter effector proteins may also suppress plant defense responses. We previously reported that transient expression of hypothetical protein effector 1 (HPE1) from either LsoA or LsoB suppresses effector-triggered immunity (ETI)-like programmed cell death (HR) induced by Prf ${ }^{\mathrm{D} 1416 \mathrm{~V}}$ and BAX in N. benthamiana [24]. However, how HPE1 suppresses host plant immunity and/or what (if any) factors it may interact with in planta are unknown.

Here, we discovered possible binding partners of HPE1 and attempted to investigate the underlying biochemical mechanisms involved in the suppression of ETI-like immune response by HPE1. We first screened a tomato yeast two-hybrid (Y2H) library and identified RAD23e as a potential HPE1 binding partner. We then confirmed the interaction between HPE1 from Lso haplotypes A and B, and different RAD23 proteins from tomato and the potato psyllid. We further examined the subcellular localization of these proteins, and characterized the potential role of HPE1 in the plant UPS. Lastly, we confirmed a functional 
role of HPE1 as a virulence factor in planta with transgenic tomato plants over-expressing HPE1. However, the direct functional linkage to the suppression of ETI is still unclear.

\section{Results}

\subsection{HPE1 Interacts with the Ubiquitin-Like Domain from Tomato RAD23c, RAD23d,} and RAD23e

A prey $\mathrm{Y} 2 \mathrm{H}$ library generated by pooling the cDNAs from Lso-uninfected, and LsoBinfected tomato leaves were screened using the HPE1 protein from LsoB as bait. After screening up to $2 \times 10^{6}$ individual yeast clones, we identified 16 clones having three different in-frame insert sequences. Of these, 14 clones had identical coding sequences, which we refer to here as HPE1 Interacting Clone 1 (HIC1). BLASTx analysis against the tomato reference genome (Solanum lycopersicum iTAG2.4) revealed that HIC1 corresponds to the first 45 amino acids of Solyc02g085840 (Figure 1A). Solyc02g085840 is RAD23e, a member of the RAD23 protein family that includes three other tomato proteins, RAD23a (Solyc03g117780), RAD23c (Solyc04g007120), and RAD23d (Solyc02g063130) [25]. HIC1 encodes the N-terminal ubiquitin-like domain (UBL) of RAD23e (Figure 1B), a domain that is assumed to interact with the $26 \mathrm{~S}$ proteasome complex [26]. Because RAD23 serves as the principal shuttle protein for ubiquitinated targets to $26 \mathrm{~S}$ proteasome, and is conserved in eukaryote species, we hypothesized that a homologous Rad23 gene might exist in psyllids. Therefore, we datamined the B. cockerelli transcriptome and identified a RAD23 homolog, which shared $51 \%, 47 \%, 51 \%$, and $50 \%$ of similarity with SIRAD23a, SIRAD23c, SIRAD23d, and SIRAD23e, respectively (Figure 1B) [10].

A

\section{RAD23e (Solyc02g085840)}

HIC1

B

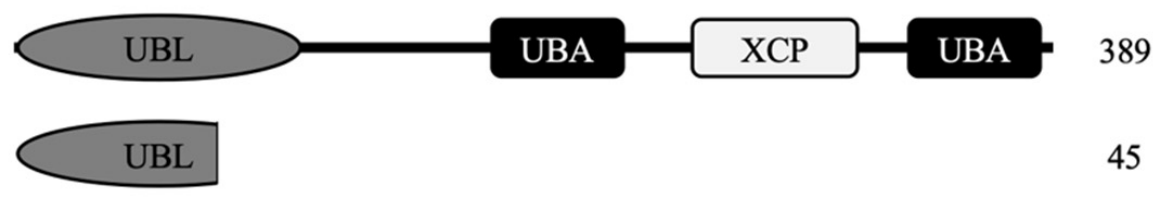

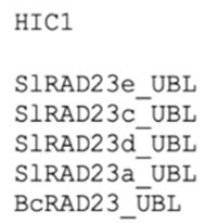

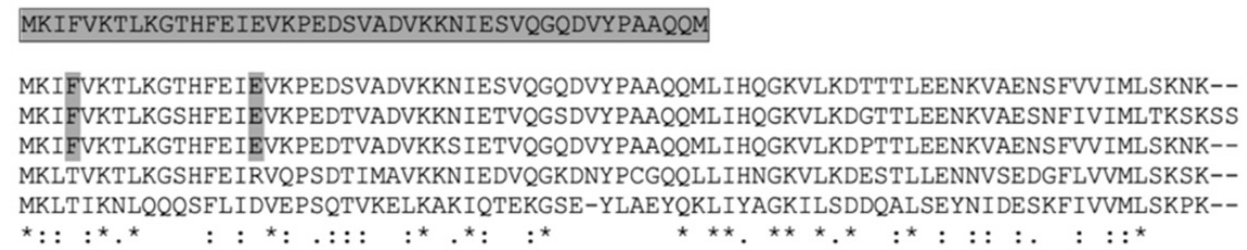

Figure 1. Sequence analysis of the HPE1 interacting clone, HIC1, identified in yeast two-hybrid screening. (A) Protein structure of the HIC1 and its full-length encoding protein, RAD23e. (B) Amino acid sequence alignment of the ubiquitin-like domain (UBL) of RAD23 proteins from Solanum lycoperisicum and Bactericera cockerelli. Asterisk, colon and dot denote the conserved and similar amino acid residues.

To evaluate if HPE1 from both Lso haplotypes interacted with the full-length SIRAD23e protein, we performed directed $\mathrm{Y} 2 \mathrm{H}$ using either HPE1A or HPE1B as bait, and the fulllength SIRAD23e as prey. Our results showed that both HPE1 from LsoA and LsoB interact with SIRAD23e (Figure 2A). Interestingly, the interaction was only observed using less stringent selection conditions (triple nutrient dropout instead of quadruple nutrient dropout as used in $\mathrm{Y} 2 \mathrm{H}$ screening), which indicated that the tertiary structure of SIRAD23e protein may affect its relative binding affinity to HPE1.

Because tomato encodes four Rad23 genes, we used Y2H to test if HPE1A and HPE1B interacted with the three remaining RAD23 proteins. Whereas, binding interactions were observed between HPE1 from both haplotypes and SIRAD23c and SIRAD23d, no interaction was observed with SIRAD23a for either haplotype (Figure 2B). Similarly, we also tested if $B$. cockerelli RAD23 interacted with HPE1B and found that neither the full-length 
BcRAD23, or the BcRAD23 UBL domain alone bound HPE1 (data not shown). These results suggest that HPE1 specifically interacts with the UBL domain of tomato SIRAD23c, SIRAD23d, and SIRAD23e.

A

\begin{tabular}{|c|c|c|c|c|c|c|c|}
\hline & & \multicolumn{3}{|c|}{ SD -Leu-Trp } & \multicolumn{3}{|c|}{ SD -Leu-Trp -His } \\
\hline $\mathrm{BD}$ & $\mathrm{AD}$ & 1 & $10^{-1}$ & $10^{-2}$ & 1 & $10^{-1}$ & $10^{-2}$ \\
\hline HPE1A & SIRAD23e & & & & & & \\
\hline Empty & SIRAD23e & & & & & & \\
\hline Lam & SV40 & & & & & & \\
\hline $\mathrm{p} 53$ & SV40 & & & & & & \\
\hline HPE1B & SIRAD23e & & & & & & \\
\hline Empty & SIRAD23e & & & & & & \\
\hline Lam & SV40 & & & & & & \\
\hline p53 & SV40 & & & & & & \\
\hline
\end{tabular}

B

\begin{tabular}{|c|c|c|c|c|c|c|c|}
\hline & & \multicolumn{3}{|c|}{ SD -Leu-Trp } & \multicolumn{3}{|c|}{ SD -Leu-Trp -His } \\
\hline $\mathrm{BD}$ & $\mathrm{AD}$ & 1 & $10^{-1}$ & $10^{-2}$ & 1 & $10^{-1}$ & $10^{-2}$ \\
\hline HPE1A & SIRAD23a & & & & & & \\
\hline HPE1A & SIRAD23c & & & & & & \\
\hline HPE1A & SIRAD23d & & & & & & \\
\hline HPE1B & SIRAD23a & & & & & & \\
\hline HPE1B & SIRAD23c & & & & & & \\
\hline HPE1B & SIRAD23d & & & & & & \\
\hline Lam & SV40 & & & & & & \\
\hline p53 & SV40 & & & & & & \\
\hline
\end{tabular}

Figure 2. Validation of HPE1 and RAD23 interactions by directed Y2H. (A) Y2H test of interaction between SIRAD23e and the HPE1 from LsoA and LsoB. pGBKT7 (BD) constructs were used as bait, and pGADT7 (AD) constructs were used as prey in Y2H. Lam + SV40 indicates negative control for $\mathrm{Y} 2 \mathrm{H}$; p53 + SV40 indicates positive control for $\mathrm{Y} 2 \mathrm{H}$. (B) Interaction between HPE1 proteins and the other SIRAD23 proteins.

\subsection{HPE1B Colocalizes and Interacts with SIRAD23e in Both Plant Nuclei and Cytosol}

The subcellular localization of HPE1B and of SIRAD23e were evaluated by transiently expressing each protein fused to a yellow fluorescent protein (YFP) in tobacco leaves. When expressed in tobacco epidermal cells, both HPE1B and SIRAD23e presented a nuclear-cytosolic localization pattern (Figure 3A). In addition, because CLIBASIA_00460, the Las homologous gene of HPE1B, displays a temperature-dependent nuclear accumulation pattern [23] — we, therefore, examined HPE1 subcellular localization at elevated temperature $\left(32^{\circ} \mathrm{C}\right)$. However, unlike CLIBASIA_00460 delocalized from nuclei, HPE1B maintained nuclear localization at higher temperatures (Figure $3 \mathrm{~A}$ ). 


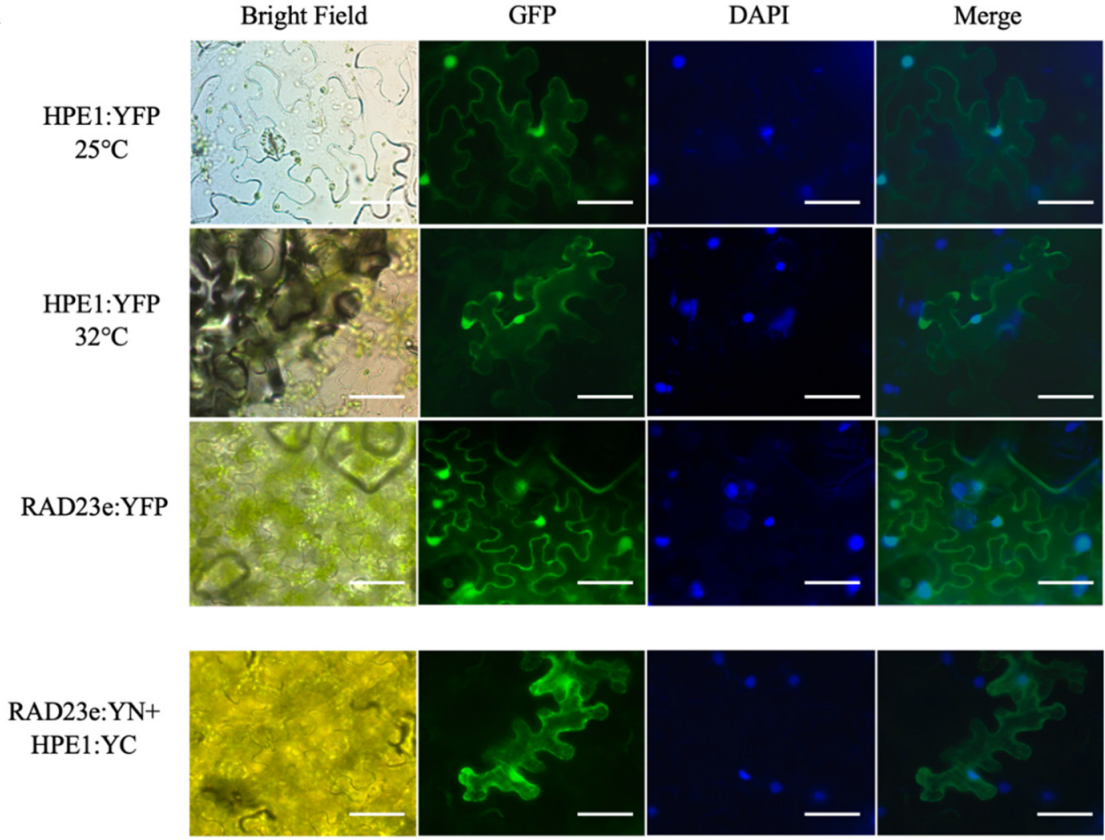

Figure 3. (A) HPE1B and RAD23e colocalized at the nuclei and cytosol of Nicotiana benthamiana epidermal cells. Upper panel: HPE1B:YFP:HA at $25^{\circ} \mathrm{C}$; Middle panel: HPE1B:YFP:HA at $32{ }^{\circ} \mathrm{C}$; Lower panel: SIRAD23e:YFP:HA at $25^{\circ} \mathrm{C}$. Scale bar $=50 \mu \mathrm{m}$ (B) Bi-molecule fluorescence complementation (BiFC) analysis of HPE1B and RAD23e interaction in N. benthamiana epidermal cells infiltrated with a 1:1 ratio of agrobacteria containing HPE1B-YC and RAD23e-YN. Images were taken between $48-60 \mathrm{~h}$ postinfiltration.

Because HPE1B and SIRAD23e colocalized in planta, we investigated the binding of the two proteins by bi-molecule fluorescence complementation (BiFC). Consistent with the colocalization of the individual proteins, a clear YFP signal showing nuclear-cytosolic localization was observed in the BiFC assays (Figure $3 \mathrm{~B}$ ), suggesting a direct interaction between SIRAD23 and HPE1B.

\subsection{HPE1B and BcRAD23 Colocalize in Cultured Insect Cells}

To rule out the possibility that BcRAD23 and HPE1B are physically prohibited from binding to each other in a surrogate expressing system, we likewise examined the subcellular localization of BcRAD23 and HPE1B in cultured Trichoplusia ni (Tni) insect cells transiently expressing fluorescent chimeras of the two genes. The red fluorescent protein, mCherry, was fused to the BcRAD23 carboxyl-terminus and enhanced GFP (EGFP) was similarly fused to HPE1B. Consistent with the results in N. benthamiana, both BcRAD23 (Figure 4A) and HPE1B (Figure 4B) showed clear nuclear-cytosolic localization patterns regardless of being expressed solely or in tandem. In addition to this localization phenotype, puncta in which the two fluorescent signals colocalized were also observed in some cells (Figure 4C). Taken together, our results support that HPE1B and BcRAD23 also colocalize in insect cells.

\subsection{HPE1B Affects the Accumulation of Ubiquitinated Proteins in Tobacco}

Since RAD23 proteins have been reported to shuttle ubiquitinated proteins to the proteasome, and thus, facilitate targeted protein degradation, we first suspected that HPE1B is ubiquitinated in plant cells and goes through the typical protein degradation route mediated by the ubiquitin/26S proteasome system. This hypothesis was tested by heterologous expression of the HPE1B protein in planta. When an anti-ubiquitin antibody was used in immunoblot detection, no sign of mono- or polyubiquitinated HPE1 was detected (Figure 5A). However, proteasome-dependent degradation was observed when an anti-HA antibody detected the HPE1B:HA fusion protein. 


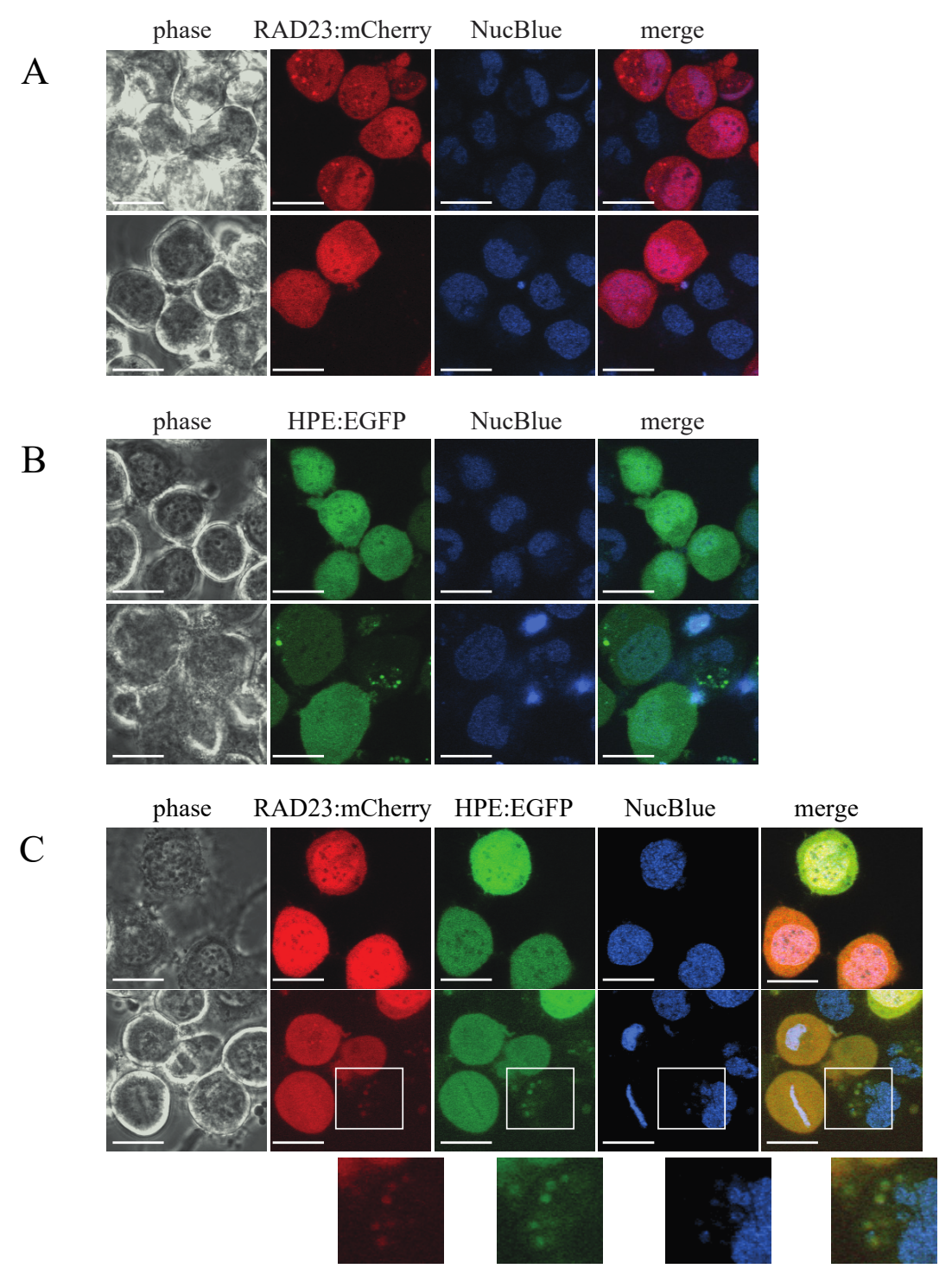

Figure 4. (A) BcRAD23e and HPE1B colocalize in the nucleus and cytosol of cultured Tni insect cells. (A) Transient expression of a red fluorescent chimera of BcRAD23 (RAD23:mCherry). (B) Transient expression of a green fluorescent chimera of HPE1B (HPE:EGFP). (C) Colocalization of the RAD23:mCherry and HPE:EGFP fluorescent signals in the cytosol and nucleus. Colocalized signals in discrete punctae were also observed in some cells (lower panel insets). Images were taken $48 \mathrm{~h}$ post-transfection with NucBlue used as a counterstain for the nucleus. Scale bar $=20 \mu \mathrm{m}$.

Next, we examined whether HPE1B expression affected the function of general ubiquitination by binding to the shuttle protein, RAD23, in plant cells. While no ubiquitination of the HPE1B fusion protein was observed as described above, the HPE1B expressing samples consistently showed a higher accumulation of other ubiquitinated proteins when compared with the control samples expressing no fusion protein (Empty vector) (Figure 5B). Moreover, these ubiquitinated proteins continued to accumulate at later time points even after transient expression of HPE1B had peaked at $48 \mathrm{~h}$ postinfection (hpi), suggesting that the degradation of HPE1B could be involved in the accumulation of ubiquitinated proteins.

Interestingly, when coexpressed with RAD23e, HPE1B appeared to be less stable as the immunoblotting could not detect the protein without the proteasome inhibitor, MG132 (Figure 5C). Overall, detection of ubiquitinated proteins by immunoblot revealed the possible inhibition of the normal shuttling function of RAD23 proteins and a decreased stability of HPE1B, resulting in the accumulation of ubiquitinated proteins in plants. 
A

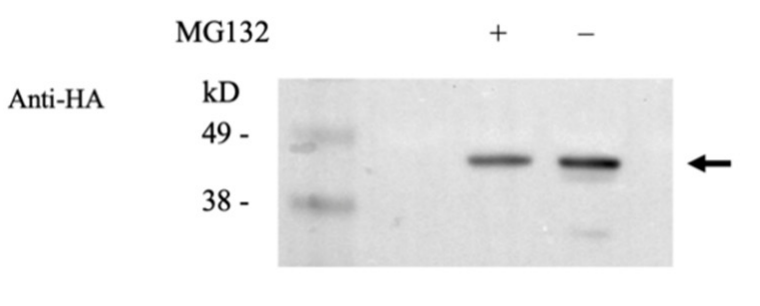

B

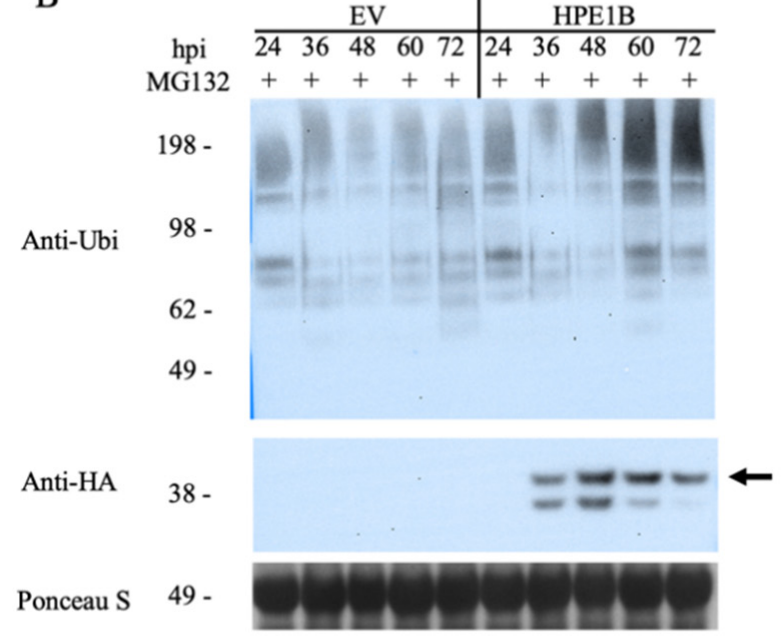

$\mathrm{C}$

\begin{tabular}{ccccccccc}
\multicolumn{1}{c}{ HPE1B/SIRAD23e } & HPE1B/SIRAD23e \\
hpi & 24 & 36 & 48 & 60 & 24 & 36 & 48 & 60 \\
MG132 & - & - & - & - & + & + & + & +
\end{tabular}

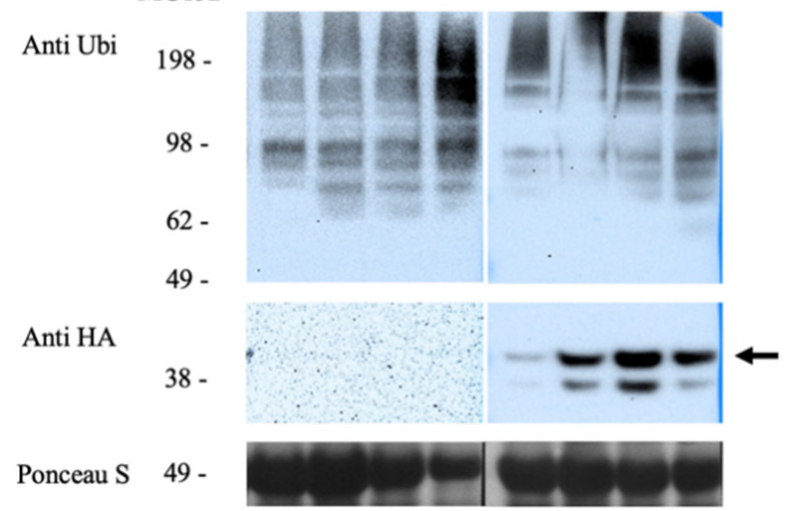

Figure 5. Immunoblot of heterologous expressing of HPE1 in N. benthamiana. (A) HPE1B is not ubiquitinated in the plant cell, but is degraded in a proteasome-dependent manner. MG132 + and MG132 -indicate treatment of the proteasome inhibitor, MG132. (B) Heterologous expression of HPE1B increased the accumulation of ubiquitinated proteins in N. benthamiana. HPE1B = HPE1B-YC, EV: empty vector. hpi indicates hours postinfiltration. (C) Coexpression of HPE1B and SIRAD23e further decreases the stability of HPE1 proteins in N. benthamiana. SIRAD23e = SIRAD23e-YN Arrow indicates the expected size of HPE1B fusion protein.

\subsection{Lso Infection Results in the Accumulation of Ubiquitinated Proteins}

We further investigated whether Lso infection leads to a disturbance in UPS in tomatoes. A difference in the abundance of ubiquitinated proteins was observed in the upper leaves of tomato plants at 4 and 6 weeks postinfection (Figure 6A). When the ubiquitin signal was quantified for the protein size ranging between $60 \mathrm{kDa}$ to $200 \mathrm{kDa}$, a statisti- 
cally significant difference was observed between the LsoB-infected and mock-inoculated groups (Figure 6B).

A

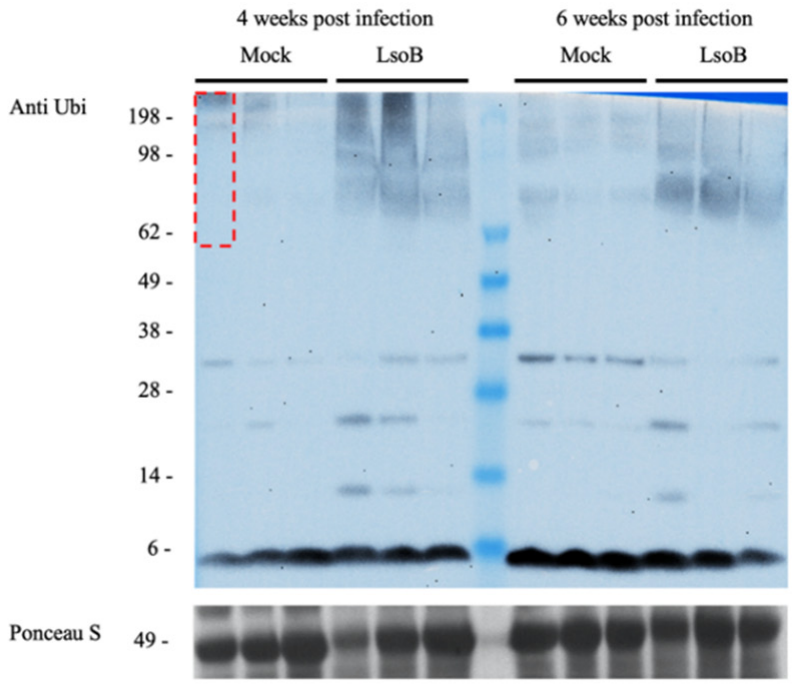

B

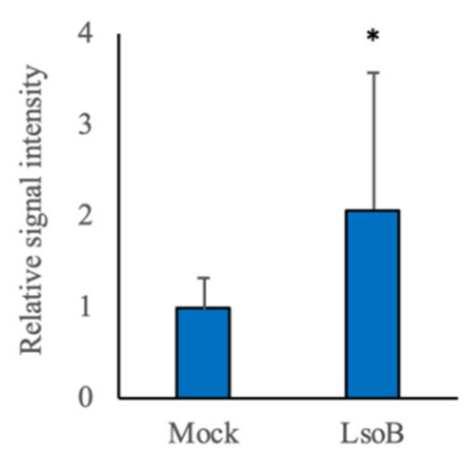

Figure 6. Immunoblot of tomato leaves at 4 weeks and 6 weeks post-LsoB infection. (A) Plants were infested with either Lso-free (Mock) or LsoB-infected (LsoB) adult psyllids. The dotted box indicates the range (60-200 kDa) used to quantify the ubiquitin signal intensity in (B). Error bars indicate the standard deviation (SD). Asterisk indicates significant difference from Mock group by Student's $t$-test $(p<0.05)$. The experiment was replicated three times, each with three plants in each group. The Western blot was repeated at least twice per sample, each showing similar results.

\subsection{Overexpressing HPE1B Facilitates LsoB Colonization and the Development of Symptoms}

To further investigate the function of HPE1 on its host plant, transgenic tomatoes expressing HPE1B were generated. We specifically included both the full-length and the mature protein of HPE1B for accessing the complete effects that HPE1B may have on tomato plants. For both types of HPE1B transgenic plants, the expression of HPE1B was confirmed at both the RNA and protein levels (data not shown). No apparent defects in plant growth and development were observed in $T_{0}$ plants. These $T_{0}$ plants were then inoculated with LsoB, and the progression of Lso colonization was determined based on the PCR detection method [27], and the development of symptoms.

Interestingly, LsoB was detected in more $\mathrm{T}_{0}$ plants $(58.8 \%, 34$ plants) than in wildtype plants $(46.2 \%, 13$ plants) at three weeks postinfection (Figure 7A). Furthermore, the typical progression of symptoms for LsoB infected plants, which begins at seven 
weeks postinfection, manifests with stunting and leaf discoloration, then transitions to leaf necrosis, and finally plant death. In three independent infection experiments, the onset of stunting and necrosis, due to infection at the shoot tip in the transgenic plants occurred earlier than the typical seven weeks postinfection in the wild-type plants (Figure 7B). Together, our results indicated that HPE1 is a positive virulent factor that can facilitate LsoB colonization in tomatoes, as well as accelerate the onset of perceived symptoms, possibly through the perturbance of SIRAD23 functions.

A

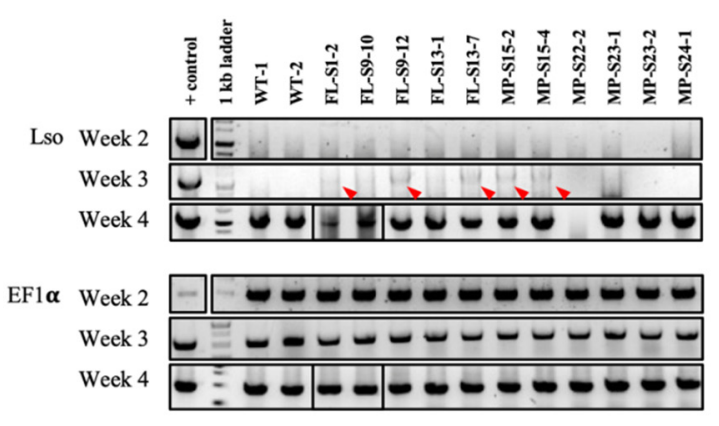

B

WT + LsoB
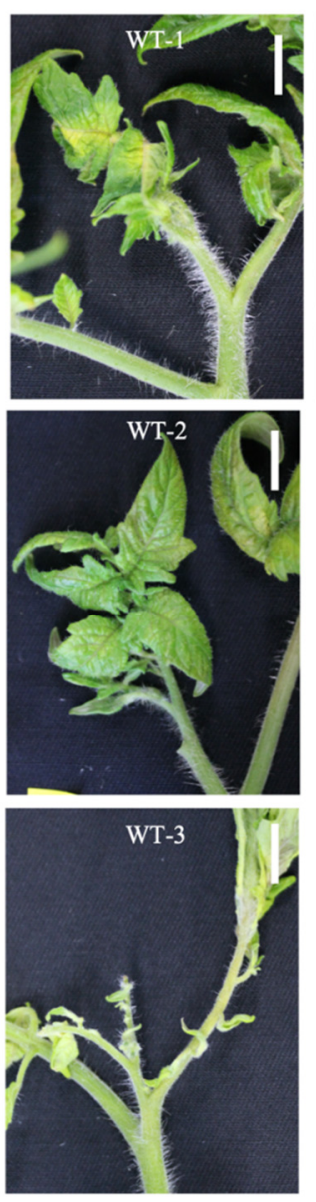

$\mathrm{FL}+\mathrm{LsoB}$
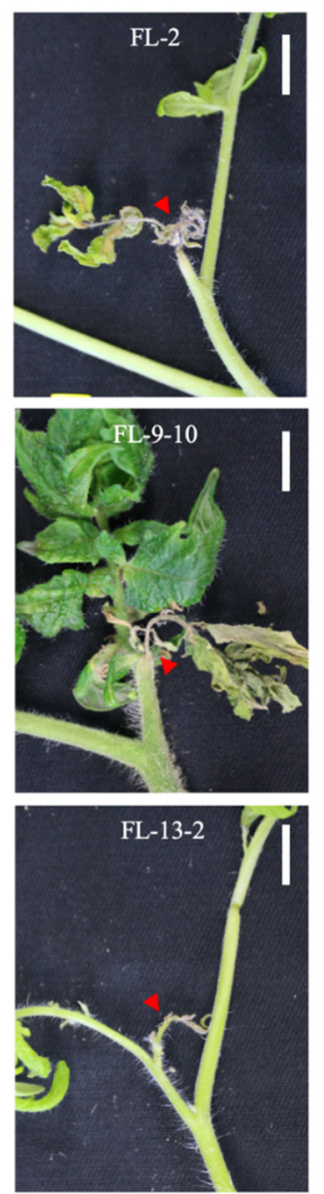

$\mathrm{MP}+\mathrm{LsoB}$
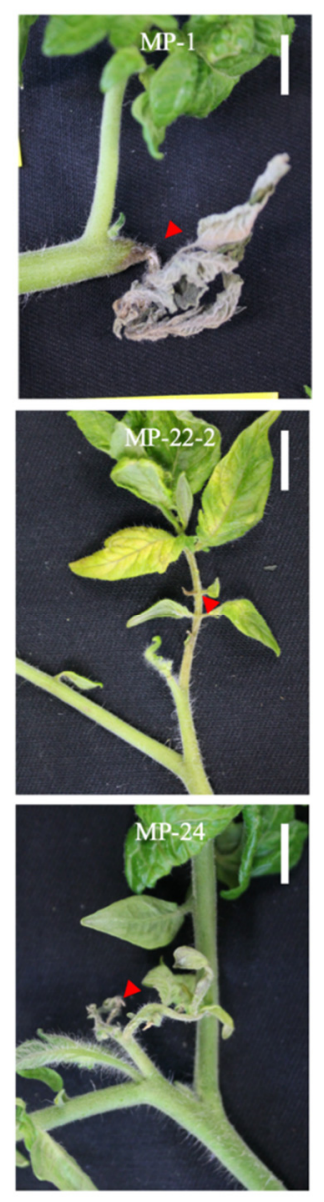

Figure 7. Lso colonization in wild-type and HPE1 transgenic tomato plants. (A) PCR detection of Lso at 2-, 3-, and 4-week postinfection. WT, wild-type; FL, full-length HPE1B; MP, mature protein HPE1B. Arrowhead indicates the expected band of the Lso PCR product. (B) Symptom development was examined at 7 weeks postinfection. Arrowhead indicates the necrosis symptom of the shoot tip observed. Scale bar $=1 \mathrm{~cm}$. 


\section{Discussion}

Despite the substantial global economic impact of Liberibacter pathogens, our understanding of the molecular mechanisms involved in host infection and disease progression remains superficial. Although novel methods for screening antimicrobial compounds have been developed [28,29], increased understanding of the virulent mechanism can reveal precise targets in the pathosystems for creating new disease control strategies. More than 200 potential effectors have been reported from Liberibacter pathogens, but only about a dozen have been functionally characterized. In this study, we extend our findings that the Sec translocon-dependent effector, HPE1, is involved in evading and/or suppressing the ETI-like immune response in tobacco. We investigated the effector by identifying the potential molecular targets of HPE1 in tomatoes by using the $\mathrm{Y} 2 \mathrm{H}$ approach, and then examined the possible function of HPE1 on proteasome degradation. We also showed that it is likely that impaired RAD23 function by HPE1 over-expression resulted in perturbation of UPS. Lastly, we found that LsoB colonization was facilitated on HPE1B over-expressing transgenic tomatoes, which provided evidence connecting HPE1 to the virulence of Lso.

We identified a prey clone, encoding the partial UBL domain of RAD23, interacting with HPE1 by $\mathrm{Y} 2 \mathrm{H}$ screening. One of the pitfalls of $\mathrm{Y} 2 \mathrm{H}$ is identifying false positive interactions, due to forced heterologous expression in the yeast cells. To strengthen the confidence of observed interactions between HPE1 and SIRAD23 proteins, and gain information on the subcellular localization of these proteins, we performed agroinfiltrations to transiently express these target proteins. Results from the agroinfiltration and BiFC confirmed the colocalization and interaction of these two proteins in the cytosol and the nucleus. Transient expression by agroinfiltration has been widely applied in plant systems and was used to discover temporal-spatial changes of proteins in vivo. For example, CLIBASIA_00460, the homologous gene of HPE1 in Las, was found to exhibit temperature-dependent nuclear translocation [23]. CLIBASIA_00460 is a potential virulence factor that positively correlated with Las pathogenicity [30]. Similar to HPE1, consistent expression during pathogen infection was detected for CLIBASIA_00460 [31]. However, the two SDEs do not share the temperature-dependent-nuclear translocation pattern (Figure 2A). This may be explained by the low sequence similarity of HPE1 and CLIBASIA_00460 (60\% amino acid sequence similarity). It is possible that these two genes have evolved host-specific functions, and it is worth investigating the potential interactors of CLIBASIA_00460 in citrus.

RAD23 is a broadly conserved protein family; it consists of three to eight members in eudicot plant species: Four members in Arabidopsis (AtRAD23a-AtRAD23d) [26], and four members in tomato (SIRAD23a-SIRAD23e) [25]. The main cellular function of RAD23 is to shuttle ubiquitin-conjugated proteins to the $26 \mathrm{~S}$ proteasome. This function is achieved by the four conserved domains in RAD23 proteins: One UBL domain, one XCP domain, and two UBA domains. It is believed that UBA acts as a substrate-binding domain to recruit polyubiquitinated substrate proteins, while UBL is the interacting domain with RPN1 or RPN10 of the $26 \mathrm{~S}$ proteasome complex, and thus, helps release the polyubiquitinated substrates for degradation. As a result, RAD23 facilitates the protein turnover of selected substrates. Tomato Stress-Associated Protein 4 (SISAP4) is a known substrate of SIRAD23, that binds to the first UBA domain, possibly resulting in the degradation of substrate proteins involved in reactive oxygen species (ROS) generation [25]. Direct interaction of Arabidopsis RAD23 proteins with the phytoplasma effecter SAP54 was reported and resulted in the degradation of substrate MADS box transcription factors that are related to the phyllody symptom [17]. Unlike SISAP4, which binds the UBA domain, our results showed that HPE1 interacts with the UBL domain of SIRAD23e. Furthermore, HPE1 selectively interacts with RAD23c, RAD23d, and RAD23e, suggesting that HPE1 does not interact with RAD23 as a ubiquitin receptor mimic, since the hydrophobic patch (Leu-8, Ile44, Val-70) critical for RPN10 binding is conserved in all SIRAD23 proteins. In yeast, RAD23 interaction with the proteasome is regulated by the phosphorylation status of the UBL domain, and the substrate turnover was inhibited when the RAD23-proteasome interaction 
was perturbed [32]. This may explain the accumulation of ubiquitinated proteins we observed in the transient expression of HPE1 in tobacco.

Another possible role of HPE1 is in disruption of the mechanism that RAD23 uses to evade proteasome-mediated degradation. RAD23 proteins can escape degradation because they lack an appropriate proteasome initiation region [33]. An addition of 44-102 amino acids after the UBL domain led to the initiation of degradation. The HPE1 mature protein is 99 amino acids in length. By binding to RAD23, HPE1 may serve as the initiation region for degradation of the HPE1-RAD23 complex. A similar mechanism may also explain the initiation of AtMIN2 (RAD23 homolog) degradation when coexpressed with P. syringae pv. tomato DC3000 effectors, HopM1 and AvrE [34]. Further study on the stability of RAD23 in the presence of HPE1 will be needed to test this hypothesis.

Emerging evidence shows that RAD23 plays important role in the colonization of hosts by pathogens and modification of plant immunity to multiple pathogens. Phytoplasma is the most extensively studied case where the pathogen manipulates AtRAD23 to reshape flower development to the pathogen's benefits [17]. Silencing of RAD23 in barley was found to decreased the secondary hyphal growth of the powdery mildew pathogen, suggesting a positive regulating role of the pathogenesis [35]. AtRAD23 was suggested to be involved in the regulation of Arabidopsis susceptibility to the non-pathogen P. syringae pv. phaseolicol, possibly by promoting target degradation in collaboration with AtSAP9 [36]. In tomatoes, SISAP4 interacts with RAD23 proteins and controls the generation of ROS that leads to localized plant cell death, which is favorable to the colonization by the necrotrophic pathogen Botrytis cinerea, but not the biotrophic pathogen P. syringae pv. tomato DC3000 [25]. In our study, we showed that the turnover of ubiquitinated proteins in plants expressing HPE1 was perturbed, possibly due to the direct interaction of HPE1 and RAD23. We also showed that HPE1 overexpressing transgenic plants promotes the colonization of at least one haplotype of Lso. It would be intriguing to study whether the function of the proteasome is attenuated, due to HPE1 and RAD23 interaction.

As described by Üstün et al. [37], the $26 \mathrm{~S}$ proteasome is largely involved in plant immunity, particularly in defense response signaling. Many plant immune signaling factors, such as the PAMP receptor FLS2, the regulator of salicylic acid-dependent defense NPR1, or the transcription factor WRKY45, are degraded through specific E3 ubiquitin ligases and the $26 \mathrm{~S}$ proteasome pathway. Besides, several proteasome subunits have been identified to contribute directly to defense responses, such as ROS production and HR development. The $\beta 1$ subunit of the $20 \mathrm{~S}$ core proteasome $(\mathrm{CP})$ was shown to be a negative regulator of early plant responses to the fungal elicitor, cryptogein [38]. PBA1, the main catalytic subunit of the $\mathrm{CP}$, was found to act as a caspase-like enzyme during the induction of programmed cell death [39]. RPN1a, a component of the $19 \mathrm{~S}$ regulatory particle, was found to be required for resistance against biotrophic fungi. A critical intracellular innate immune receptor protein RESISTANCE TO PSEUDOMONAS MACULICOLA1 (RPM1) for $P$. syringae effector-triggered HR is well known to be dependent on the proper $26 \mathrm{~S}$ proteasome-mediated degradation to be functional. Considering the broad involvement of UPS in the plant immune system, it is not surprising that plant pathogens exploit effectors that target the UPS to their benefit [37,40,41].

Although no effector-triggered immunity has been identified for Liberibacter pathogens to date [42], our previous identification of HPE1 was one of the first reported suppressors of the ETI-like immune response from phloem inhabiting pathogens. In this study, we attempted to investigate the mechanism behind the immune suppressor role of HPE1. However, from our current results, it is still not clear how the expression of HPE1 in plants inhibits Prf ${ }^{\mathrm{D} 1416}$ triggered HR cell death. It is possible that polyubiquitinated HR signaling components are not shuttled properly to the proteasome, due to the HPE1-RAD23 interaction. It will be important to further identify the possible substrate proteins of the HPE1-RAD23 complex involved in the plant defense pathway. We proposed that approaches, such as yeast-three hybrid screening [43] and ubiquitylome screening [44], can extend our understanding of the fine manipulation of host proteostasis during Lso infec- 
tion. Last, but not least, we showed that expression of HPE1B in transgenic tomato plants enables the progression of Lso infection, and further studies using different Lso haplotypes may enhance our understanding of the underlying mechanisms of Lso infection.

\section{Materials and Methods}

\subsection{Plant and Psyllid Populations for Lso Infection}

Tomato (Solanum lycopersicum L. 'Moneymaker'; Thompson and Morgan Inc., Jackson, NJ, USA) plants and tobacco (Nicotiana benthamiana) were grown from seed in pots with Sun Gro Sunshine LP5 mix (Bellevue, WA, USA) and fertilized twice a week with MiracleGro Water-Soluble Tomato Plant Food at the label rate (18-18-21 NPK; Scotts Miracle-Gro Company, Marysville, OH, USA). One-week-old seedlings were transplanted to individual pots and let grow in the same conditions.

Lab-reared ' $\mathrm{C} a$. Liberibacter solanacearum'-free and LsoB-infected psyllid populations were maintained separately on tomato plants in insect-proof cages ( 24 by 13.5 by $13.5 \mathrm{~cm}$; BioQuip, Compton, CA, USA) at room temperature $\left(24^{\circ} \mathrm{C}\right)$ and under a photoperiod of $16 \mathrm{~h}$ light- $8 \mathrm{~h}$ dark, as described previously [45]. These psyllid populations are henceforth referred to as Lso-free, and LsoB populations, respectively.

For Lso infection, five-week-old tomato seedlings were used, and four adult psyllids from the desired population were mesh-bagged with a lower-tier leaf for seven days before being removed. Each infection experiment had at least three plants, and the experiments were repeated at least three times.

\subsection{RNA Extraction}

One hundred $\mathrm{mg}$ of leaf samples from the top-tier leaves were collected and flashfrozen in liquid nitrogen for storage at $-80^{\circ} \mathrm{C}$ before extraction of RNA. Trizol reagent (Invitrogen, Carlsbad, CA, USA) was used for the RNA extraction following the user's manual. TURBO DNA-free (Life Technologies, Carlsbad, CA, USA) was used for removing DNA. For detection of gene expression, a Verso cDNA synthesis kit (Life Technologies, Carlsbad, CA, USA) was used to generate first-strand cDNA.

\subsection{Y2H Library Preparation}

A cDNA library was constructed using the Make Your Own "Mate and Plate" Library System (Takara Bio, San Jose, CA, USA) following the user's manual. Briefly, RNA from Lsofree-, and LsoB-infected tomato leaves were obtained and pooled to increase the transcript representation. Double strand cDNA was generated from $1 \mu \mathrm{g}$ of pooled tomato RNA by 'SMART' MMLV Reverse Transcriptase with SMART III Oligo and CDSIII/ 6 primer. The cDNA pool was amplified by long-distance PCR (LD-PCR) using Advantage 2 PCR Premix (Takara Bio, San Jose, CA, USA) with the following conditions: Initial denaturation step at $95^{\circ} \mathrm{C}$ for $30 \mathrm{~s}$; followed by 20 cycles of $95^{\circ} \mathrm{C}$ for $30 \mathrm{~s}, 68^{\circ} \mathrm{C}$ for 6 min with $5 \mathrm{~s}$ increment of extension time per cycle; then a final extension step at $68^{\circ} \mathrm{C}$ for $5 \mathrm{~min}$. Size selection of the cDNA was made by Chroma Spin TE- 400 column. The resulting cDNA inserts were cloned into prey vector by an in vivo recombination approach $-4 \mu \mathrm{g}$ of tomato cDNA was cotransformed with $3 \mu \mathrm{g}$ of linearized pGADT7-Rec vector into yeast (Saccharomyces cerevisiae) strain Y187 following the user's manual of Yeastmaker Yeast Transformation System 2 (Takara Bio, San Jose, CA, USA) and plated on leucine dropout minimal medium (SD-Leu). After four days of incubation at $30^{\circ} \mathrm{C}$, yeast cells were harvested using a freezing medium (YPDA+ 15\% glycerol). The quality of the cDNA library was evaluated based on the colony-forming unit ( $\mathrm{cfu}$ ) on the selection medium and by the final titer of the pooled library.

\subsection{Yeast Two Hybrid Screening and Directed $Y 2 \mathrm{H}$}

The sequence encoding the mature protein (without signal peptide) of HPE1B (Accession number: WP_013462289) was cloned into the EcoRI and BamHI sites of a pGBKT7 vector. The construct was sequenced and confirmed prior to transformation into the Match- 
maker $\mathrm{Y} 2 \mathrm{H}$ Gold yeast strain. The bait strain was cultured in SD-Trp medium and brought to a final concentration of $>10^{8}$ cells $/ \mathrm{mL}$. Mating was performed by combining $5 \mathrm{~mL}$ of bait cells with $1 \mathrm{~mL}$ of prey library $\left(>2 \times 10^{7}\right.$ cells $/ \mathrm{mL}$ for each screen) supplemented with $2 \times$ YPDA media at $30{ }^{\circ} \mathrm{C}$ for $24 \mathrm{~h}$ at $35 \mathrm{rpm}$. Mated cells were collected and resuspended in sterilized water and plated on a selective quadruple dropout medium (SD - Leu/-Trp/-His/-Ade, QDO). After incubation at $30{ }^{\circ} \mathrm{C}$ for 7 days, yeast colonies that grew well were subjected to colony PCR following the method described in the Yeast Protocol handbook (Clontech, San Jose, CA, USA), and the PCR products were sequenced. Positive colonies were transferred to a new selection medium to confirm growth and interaction intensity. Plasmids of these positive clones were rescued according to the Matchmaker Library Construction and Screening Kits (Takara Bio, San Jose, CA, USA) protocol and subjected to sequencing. The insert sequences for these positive clones were used to BLAST against the tomato genome (iTAG2.4) using the Phytozome v12 database (https:/ / phytozome.jgi.doe.gov/pz/portal.html, accessed date: 25 July 2020).

For directed $\mathrm{Y} 2 \mathrm{H}$, full-length SIRad 23 and Bactericera cockerelli Rad 23 coding sequences were cloned into the GADT7 vectors as prey, and the coding sequence of the mature HPE1A protein was cloned into pGBKT7 as bait. The desired pair of prey and bait constructs were cotransformed into Y2H Gold yeast and plated on SD-Leu-Trp (DDO) medium. Yeast clones with paired constructs were cultured, and $10 \mu \mathrm{L}$ droplets of the culture dilutions were transferred onto DDO, SD-Leu-Trp-His (TDO), and QDO with a supplement of $40 \mu \mathrm{g} / \mathrm{mL}$ X-alpha-Gal.

\subsection{Agroinfiltration and Bi-Molecular Fluorescence Complementation}

The HPE1B coding region for mature protein was amplified from DNA extracted from psyllids harboring LsoB. The full-length CDS of the SlRad23e gene was amplified from tomato cDNA. PCR was performed using Phusion High-Fidelity DNA Polymerase and gene-specific primers described in Supplementary Table S1. The purified amplicons were TOPO cloned into the pENTR vector according to the manufacturer's directions (Thermo Fisher Scientific, Waltham, MA, USA) and verified by sequencing. The purified pENTR vector containing HPE1B and Rad23 genes was used to subclone into a YFP containing binary expression vector, pEarlryGate101-YFP, with the Gateway LR Clonase II enzyme (Thermo Fisher Scientific, Waltham, MA, USA). The resulting constructs pHPE1:YFP and pRAD23e:YFP were transformed into Agrobacterium tumefaciens strain LBA4404 by electroporation.

For BiFC assays, previously cloned pENTR constructs were used to subclone the RAD23e coding sequence into the pEarleyGate201-YN vector, and HPE1B (without signal peptide) was cloned into pEarleyGate202-YC using LR Clonase II. The full-length YFP function is complemented when targeted proteins physically interact with each other, as described by Lu et al. [46]

Transformed A. tumefaciens were grown at $28{ }^{\circ} \mathrm{C}$ for $16-24 \mathrm{~h}$, in the LB medium containing $10 \mathrm{mM}$ morpholinnehanesulfonic acid (MES) pH 5.6 and $20 \mu \mathrm{M}$ acetosyringone (AS). The cultures were pelleted and resuspended in freshly prepared infiltration buffer $\left(10 \mathrm{mM} \mathrm{MgCl} 2,10 \mathrm{mM}\right.$ MES, and $200 \mu \mathrm{M}$ AS) to a final $\mathrm{OD}_{600}=0.8$. Cells were incubated in the dark for at least $4 \mathrm{~h}$ at room temperature. Agrobacterium carrying pEarleyGate101 or BiFC constructs (coinfiltration at $v / v$ ratio $=1: 1$ ) infiltrated into the intercellular spaces the leaves of 4-week-old N. benthamiana plants with a needleless syringe. For temperaturedependent localization assay, $N$. benthamina plants were transferred to a controlled growth chamber set at $32{ }^{\circ} \mathrm{C}$ for three days before agroinfiltration. After infiltration, the plants were maintained at $32{ }^{\circ} \mathrm{C}$ until microscopically examined using a fluorescent microscope (Axio Imager A1 microscope, Carl Zeiss Microscopy, White Plains, NY, USA) with a FITC (488 nm, green) filter for YFP signal.

For immunoblot assays, leaf samples were collected at 24, 36, 48, 60, $72 \mathrm{~h}$ after agroinfiltration using a cork borer (diameter $=1.5 \mathrm{~cm}$ ). Proteasome inhibitor, MG132 (final 
concentration $=50 \mu \mathrm{M}$ ), was infiltrated to the same location $12 \mathrm{~h}$ prior to the collection time points.

\subsection{Transient Expression of Fluorescent Chimeras of HPE1 and BcRAD23 in Cultured Tni} Insect Cells

Constructs encoding fluorescent chimeras of HPE1B mature protein and BcRAD23 tagged at their C-terminal ends with mCherry or EGFP (enhanced green fluorescent protein) were generated via overlap extension PCR [47], and then cloned into the pIB/v5-His insect cell expression vector (Thermo Fisher Scientific, Waltham, MA, USA). Overlap extension PCR was performed using KOD-Hot Start DNA polymerase (EMD Millipore, San Diego, CA, USA) as described [48] with sequence-validated plasmids and primers listed in Table S1. Initial thermocycler conditions consisted of $95^{\circ} \mathrm{C}$ for $2 \mathrm{~min}$ followed by 25 cycles at $95^{\circ} \mathrm{C}$ for $20 \mathrm{~s}, 58^{\circ} \mathrm{C}$ for $20 \mathrm{~s}, 70^{\circ} \mathrm{C}$ for $1: 30 \mathrm{~min}$, and a final extension at $70{ }^{\circ} \mathrm{C}$ for $5 \mathrm{~min}$. Final thermocycler conditions consisted of $95^{\circ} \mathrm{C}$ for $2 \mathrm{~min}$ followed by 27 cycles at $95^{\circ} \mathrm{C}$ for $20 \mathrm{~s}, 56^{\circ} \mathrm{C}$ for $20 \mathrm{~s}, 70{ }^{\circ} \mathrm{C}$ for $1: 30 \mathrm{~min}$, and a final extension at $70{ }^{\circ} \mathrm{C}$ for $5 \mathrm{~min}$. Clones were sequence verified (Retrogen Inc., San Diego, CA, USA).

Cultured Trichoplusia ni (Tni) cells (Allele Biotech Inc., San Diego, CA, USA), an embryonic insect cell line [49], were transfected on 35-mm \#1.5 glass-bottom dishes (Matsunami Glass USA Inc., Bellingham, WA, USA) as described [48] using Cellfectin II (Thermo Fisher Scientific Waltham, MA, USA). Localization of the transiently expressed chimeras was examined $48 \mathrm{hr}$ post-transfection using a $60 \times$ phase contrast water immersion objective/NA 1.2 on a FluoView FV10i laser scanning confocal microscope (Olympus Scientific Solutions, Waltham, MA, USA). Images were processed using Photoshop 21.2.9 (Adobe Inc., Mountain View, CA, USA).

\subsection{Protein Extraction and Immunoblotting}

Plant samples were homogenized in protein extraction buffer $[10 \mu \mathrm{M}$ Tris-HCL, $0.5 \mu \mathrm{M}$ EDTA, $0.4 \mu \mathrm{M}$ DTT, 1X Protease inhibitor cocktail (Thermo Fisher scientific, Waltham, MA, USA)]. Total protein extracts were quantified by Bradford assay. Around $10 \mu \mathrm{g}$ of proteins mixed with 4 X SDS sample buffer were loaded onto each lane of a 4-12\% Bis-Tris NuPage gel (Invitrogen, Carlsbad, CA, USA). Proteins were transferred to ImmobilonP PVDF membrane (Millipore-Sigma, Burlington, MA, USA) using standard blotting protocol. Ponceau $S$ staining was used to visualize protein loading. The membrane was then blocked with 5\% dry milk in TBST buffer followed by incubation with the desired primary antibody [anti-HA (Invitrogen, Carlsbad, CA, USA), anti-Ubiquitin (Cytoskeleton Inc., Denvor, CO, USA), or anti-FLAG (Millipore-Sigma, Burlington, MA, USA)] at $4{ }^{\circ} \mathrm{C}$ overnight. After washing off the primary antibody, the blot was incubated with HRPconjugated goat anti-mouse IgG $(\mathrm{H}+\mathrm{L})$ secondary antibody (Invitrogen, Carlsbad, CA, USA) at room temperature for $1 \mathrm{~h}$. The bound antibody was detected using the SuperSignal West Pico substrate (Invitrogen, Carlsbad, CA, USA) and imaged on an iBright 1500 imaging system (Thermo Fisher Scientific, Waltham, MA, USA). Signal intensity was analyzed and quantified using the iBright Analysis Software (Thermo Fisher Scientific, Waltham, MA, USA). Means of signal intensity were compared with Student's $t$-test.

\subsection{Generation of Transgenic Plants}

The sequences encoding the full-length or mature protein of HPE1B were cloned with BamHI and KpnI sites into the binary vector pERGFP-1380N, generating pHPE1-FL-OE, and pHPE1-MP-OE constructs under the control of the Cauliflower mosaic virus 35S promoter. The constructs were sequenced to confirm the correct insertion of the HPE1B and in-frame HA fusion tags. Transgenic tomatoes were generated at the Multi-Crop Transformation Facility at Texas A\&M University using previously described methods [50,51]. Seedlings generated from calli grew on selection media (Kanamycin) were separated into individual tubes with rooting media, and later screened by PCR using HPE1 specific primers.

Individual $\mathrm{T}_{0}$ plants were tested for HPE1 gene expression by RT-PCR and for protein expression by dot blot using an anti-HA antibody (Invitrogen, Carlsbad, CA, USA). $\mathrm{T}_{0}$ 
cutting plants were generated from the axillary shoots, and allowed to root for one week before transplanting. Two-week-old cutting plants expressing the HPE1 gene were used for Lso infection experiments. For each plant, four adult psyllids from the LsoB population were allowed to feed for seven days before being removed from the plant. Leaf samples from the second-tier leaves were collected weekly from 2 to 5 weeks postinfection to detect Lso cells by PCR as previously described. Wild-type plants were treated similarly.

Supplementary Materials: The following are available online at https://www.mdpi.com/article/ 10.3390/ijms22169003/s1, Table S1: Primers used in this study.

Author Contributions: C.-C.K., J.L., A.M.-H., J.J.H., J.A.F. and C.T. contributed to the experimental design, and the interpretation of the results. C.-C.K. wrote the original manuscript and performed the statistical analysis of data and interpreted results. All authors have read and agreed to the published version of the manuscript.

Funding: This research was funded by the United States Department of Agriculture, National Institute of Food Agriculture, Agriculture and Food Research Initiative competitive award number 2017-67013-2656, and by the Texas A\&M University and Texas A\&M AgriLife Research (Controlling Exotic and Invasive Insect-Transmitted Pathogens) and Hatch project TEX0-1-9381 Accession Number 1015773.

Institutional Review Board Statement: Not applicable.

Informed Consent Statement: Not applicable.

Data Availability Statement: The data that support the findings of this study are available upon resonable request made to the corresponding author.

Acknowledgments: Mention of trade names or commercial products in this article is solely for the purpose of providing specific information and does not imply recommendation or endorsement by the US Department of Agriculture; the USDA is an equal opportunity provider and employer.

Conflicts of Interest: The authors declare no conflict of interest.

\section{References}

1. Tang, X.-T.; Tamborindeguy, C. No evidence of apoptotic response of the potato psyllid Bactericera cockerelli to "Candidatus Liberibacter solanacearum" at the gut interface. Infect. Immun. 2019, 88, e00242-19. [CrossRef] [PubMed]

2. Mendoza-Herrera, A.; Levy, J.; Harrison, K.; Yao, J.; Ibanez, F.; Tamborindeguy, C. Infection by Candidatus Liberibacter solanacearum' haplotypes A and B in Solanum lycopersicum 'Moneymaker'. Plant Dis. 2018, 102, 2009-2015. [CrossRef] [PubMed]

3. Swisher Grimm, K.D.; Garczynski, S.F. Identification of a new haplotype of 'Candidatus Liberibacter solanacearum' in Solanum tuberosum. Plant Dis. 2018, 103, 468-474. [CrossRef]

4. Munyaneza, J.E. Zebra chip disease, Candidatus Liberibacter, and potato psyllid: A global threat to the potato industry. Am. J. Potato Res. 2015, 92, 230-235. [CrossRef]

5. Killiny, N.; Jones, S.E. Metabolic alterations in the nymphal instars of Diaphorina citri induced by Candidatus Liberibacter asiaticus, the putative pathogen of Huanglongbing. PLOS ONE 2018, 13, e0191871. [CrossRef]

6. Huot, O.B.; Levy, J.G.; Tamborindeguy, C. Global gene regulation in tomato plant (Solanum lycopersicum) responding to vector (Bactericera cockerelli) feeding and pathogen ('Candidatus Liberibacter solanacearum') infection. Plant Mol. Biol. 2018, 97, 57-72. [CrossRef] [PubMed]

7. Levy, J.G.; Mendoza, A.; Miller, J.C.; Tamborindeguy, C.; Pierson, E.A. Global gene expression in two potato cultivars in response to 'Candidatus Liberibacter solanacearum' infection. BMC Genom. 2017, 18, 960. [CrossRef]

8. Aritua, V.; Achor, D.; Gmitter, F.G.; Albrigo, G.; Wang, N. Transcriptional and microscopic analyses of citrus stem and root responses to Candidatus Liberibacter asiaticus infection. PLoS ONE 2013, 8, e73742. [CrossRef]

9. Nwugo, C.C.; Lin, H.; Duan, Y.; Civerolo, E.L. The effect of 'Candidatus Liberibacter asiaticus' infection on the proteomic profiles and nutritional status of pre-symptomatic and symptomatic grapefruit (Citrus paradisi) plants. BMC Plant Biol. 2013, 13, 59. [CrossRef]

10. Nachappa, P.; Levy, J.; Tamborindeguy, C. Transcriptome analyses of Bactericera cockerelli adults in response to "Candidatus Liberibacter solanacearum" infection. Mol. Genet. Genom. 2012, 287, 803-817. [CrossRef] [PubMed]

11. Kruse, A.; Fattah-Hosseini, S.; Saha, S.; Johnson, R.; Warwick, E.; Sturgeon, K.; Mueller, L.; MacCoss, M.J.; Shatters, R.G., Jr.; Cilia Heck, M. Combining 'omics and microscopy to visualize interactions between the Asian citrus psyllid vector and the Huanglongbing pathogen Candidatus Liberibacter asiaticus in the insect gut. PLoS ONE 2017, 12, e0179531. [CrossRef]

12. Abramovitch, R.B.; Kim, Y.-J.; Chen, S.; Dickman, M.B.; Martin, G.B. Pseudomonas type III effector AvrPtoB induces plant disease susceptibility by inhibition of host programmed cell death. EMBO J. 2003, 22, 60-69. [CrossRef] 
13. Nakano, M.; Oda, K.; Mukaihara, T. Ralstonia solanacearum novel E3 ubiquitin ligase (NEL) effectors RipAW and RipAR suppress pattern-triggered immunity in plants. Microbiology 2017, 163, 992-1002. [CrossRef] [PubMed]

14. Yang, L.; Teixeira, P.J.P.L.; Biswas, S.; Finkel, O.M.; He, Y.; Salas-Gonzalez, I.; English, M.E.; Epple, P.; Mieczkowski, P.; Dangl, J.L. Pseudomonas syringae type III effector HopBB1 promotes host transcriptional repressor degradation to regulate phytohormone responses and virulence. Cell Host Microbe 2017, 21, 156-168. [CrossRef] [PubMed]

15. Caillaud, M.-C.; Asai, S.; Rallapalli, G.; Piquerez, S.; Fabro, G.; Jones, J.D.G. A downy mildew effector attenuates salicylic acid-triggered immunity in Arabidopsis by interacting with the host mediator complex. PLOS Biol. 2013, 11, e1001732. [CrossRef] [PubMed]

16. MacLean, A.M.; Sugio, A.; Makarova, O.V.; Findlay, K.C.; Grieve, V.M.; Tóth, R.; Nicolaisen, M.; Hogenhout, S.A. Phytoplasma effector SAP54 induces indeterminate leaf-like flower development in Arabidopsis plants. Plant Physiol. 2011, 157, 831-841. [CrossRef] [PubMed]

17. MacLean, A.M.; Orlovskis, Z.; Kowitwanich, K.; Zdziarska, A.M.; Angenent, G.C.; Immink, R.G.H.; Hogenhout, S.A. Phytoplasma effector SAP54 hijacks plant reproduction by degrading MADS-box proteins and promotes insect colonization in a RAD23dependent manner. PLoS Biol. 2014, 12, e1001835. [CrossRef]

18. Langin, G.; Gouguet, P.; Üstün, S. Microbial effector proteins: A journey through the proteolytic landscape. Trends Microbiol. 2020, 28, 523-535. [CrossRef]

19. Prasad, S.; Xu, J.; Zhang, Y.; Wang, N. SEC-translocon dependent extracytoplasmic proteins of Candidatus Liberibacter asiaticus. Front. Microbiol. 2016, 7, 1989. [CrossRef]

20. Pitino, M.; Armstrong, C.M.; Cano, L.M.; Duan, Y. Transient expression of Candidatus Liberibacter asiaticus effector induces cell death in Nicotiana benthamiana. Front. Plant Sci. 2016, 7, 982. [CrossRef]

21. Thapa, S.P.; De Francesco, A.; Trinh, J.; Gurung, F.B.; Pang, Z.; Vidalakis, G.; Wang, N.; Ancona, V.; Ma, W.; Coaker, G. Genomewide analyses of Liberibacter species provides insights into evolution, phylogenetic relationships, and virulence factors. Mol. Plant Pathol. 2020, 21, 716-731. [CrossRef]

22. Clark, K.; Franco, J.Y.; Schwizer, S.; Pang, Z.; Hawara, E.; Liebrand, T.W.H.; Pagliaccia, D.; Zeng, L.; Gurung, F.B.; Wang, P.; et al. An effector from the Huanglongbing-associated pathogen targets citrus proteases. Nat. Commun. 2018, 9, 1718. [CrossRef] [PubMed]

23. Liu, X.; Fan, Y.; Zhang, C.; Dai, M.; Wang, X.; Li, W. Nuclear import of a secreted "Candidatus Liberibacter asiaticus" protein is temperature dependent and contributes to pathogenicity in Nicotiana benthamiana. Front. Microbiol. 2019, $10,1684$. [CrossRef] [PubMed]

24. Levy, J.G.; Gross, R.; Mendoza-Herrera, A.; Tang, X.; Babilonia, K.; Shan, L.; Kuhl, J.C.; Dibble, M.S.; Xiao, F.; Tamborindeguy, C. Lso-HPE1, an effector of 'Candidatus Liberibacter solanacearum', can repress plant immune response. Phytopathology 2019, 110, 648-655. [CrossRef]

25. Liu, S.; Yuan, X.; Wang, Y.; Wang, H.; Wang, J.; Shen, Z.; Gao, Y.; Cai, J.; Li, D.; Song, F. Tomato stress-associated protein 4 contributes positively to immunity against necrotrophic fungus Botrytis cinerea. Mol. Plant-Microbe Interact. 2018, 32, 566-582. [CrossRef] [PubMed]

26. Farmer, L.M.; Book, A.J.; Lee, K.-H.; Lin, Y.-L.; Fu, H.; Vierstra, R.D. The RAD23 family provides an essential connection between the 26S proteasome and ubiquitylated proteins in Arabidopsis. Plant Cell 2010, 22, 124-142. [CrossRef] [PubMed]

27. Levy, J.; Ravindran, A.; Gross, D.; Tamborindeguy, C.; Pierson, E. Translocation of 'Candidatus Liberibacter solanacearum', the zebra chip pathogen, in potato and tomato. Phytopathology 2011, 101, 1285-1291. [CrossRef]

28. Irigoyen, S.; Ramasamy, M.; Pant, S.; Niraula, P.; Bedre, R.; Gurung, M.; Rossi, D.; Laughlin, C.; Gorman, Z.; Achor, D.; et al. Plant hairy roots enable high throughput identification of antimicrobials against Candidatus Liberibacter spp. Nat. Commun. 2020, 11, 5802. [CrossRef]

29. Huang, C.-Y.; Araujo, K.; Sánchez, J.N.; Kund, G.; Trumble, J.; Roper, C.; Godfrey, K.E.; Jin, H. A stable antimicrobial peptide with dual functions of treating and preventing citrus Huanglongbing. Proc. Natl. Acad. Sci. USA 2021, 118, e2019628118. [CrossRef]

30. Ying, X.; Wan, M.; Hu, L.; Zhang, J.; Li, H.; Lv, D. Identification of the virulence factors of Candidatus Liberibacter asiaticus via heterologous expression in Nicotiana benthamiana using Tobacco mosaic virus. Int. J. Mol. Sci. 2019, 20, 5575. [CrossRef]

31. Shi, Q.; Pitino, M.; Zhang, S.; Krystel, J.; Cano, L.M.; Shatters, R.G.; Hall, D.G.; Stover, E. Temporal and spatial detection of Candidatus Liberibacter asiaticus putative effector transcripts during interaction with Huanglongbing-susceptible, -tolerant, and -resistant citrus hosts. BMC Plant Biol. 2019, 19, 122. [CrossRef]

32. Liang, R.-Y.; Chen, L.; Ko, B.-T.; Shen, Y.-H.; Li, Y.-T.; Chen, B.-R.; Lin, K.-T.; Madura, K.; Chuang, S.-M. Rad23 interaction with the proteasome is regulated by phosphorylation of its Ubiquitin-Like (UbL) domain. J. Mol. Biol. 2014, 426, 4049-4060. [CrossRef]

33. Fishbain, S.; Prakash, S.; Herrig, A.; Elsasser, S.; Matouschek, A. Rad23 escapes degradation because it lacks a proteasome initiation region. Nat. Commun. 2011, 2, 192. [CrossRef]

34. Uribe Romeo, F.J. Study of the Virulence Protein AvrE in Pseudomonas Syringae Pathogenesis; Michigan State University: East Lansing, MI, USA, 2011.

35. Bulduklu, Y.; Ersoy, F.; Akkaya, M. RAD23 as a negative regulator of barley powdery mildew disease resistance. Fresenius Environ. Bull. 2018, 27, 6239-6244. 
36. Kang, M.; Lee, S.; Abdelmageed, H.; Reichert, A.; Lee, H.-K.; Fokar, M.; Mysore, K.S.; Allen, R.D. Arabidopsis stress associated protein 9 mediates biotic and abiotic stress responsive ABA signaling via the proteasome pathway. Plant Cell Environ. 2017, 40, 702-716. [CrossRef] [PubMed]

37. Üstün, S.; Sheikh, A.; Gimenez-Ibanez, S.; Jones, A.; Ntoukakis, V.; Börnke, F. The proteasome acts as a hub for plant immunity and Is targeted by Pseudomonas type III effectors. Plant Physiol. 2016, 172, 1941-1958. [CrossRef] [PubMed]

38. Marino, D.; Peeters, N.; Rivas, S. Ubiquitination during plant immune signaling. Plant Physiol. 2012, 160, 15-27. [CrossRef] [PubMed]

39. Hatsugai, N.; Iwasaki, S.; Tamura, K.; Kondo, M.; Fuji, K.; Ogasawara, K.; Nishimura, M.; Hara-Nishimura, I. A novel membrane fusion-mediated plant immunity against bacterial pathogens. Genes Dev. 2009, 23, 2496-2506. [CrossRef]

40. Banfield, M.J. Perturbation of host ubiquitin systems by plant pathogen/pest effector proteins. Cell. Microbiol. 2015, 17, 18-25. [CrossRef]

41. Dielen, A.-S.; Badaoui, S.; Candresse, T.; German-Retana, S. The ubiquitin/26S proteasome system in plant-pathogen interactions: A never-ending hide-and-seek game. Mol. Plant Pathol. 2010, 11, 293-308. [CrossRef]

42. Jiang, Y.; Zhang, C.-X.; Chen, R.; He, S.Y. Challenging battles of plants with phloem-feeding insects and prokaryotic pathogens. Proc. Natl. Acad. Sci. USA 2019, 116, 23390-23397. [CrossRef]

43. Cottier, S.; Mönig, T.; Wang, Z.; Svoboda, J.; Boland, W.; Kaiser, M.; Kombrink, E. The yeast three-hybrid system as an experimental platform to identify proteins interacting with small signaling molecules in plant cells: Potential and limitations. Front. Plant Sci. 2011, 2, 101. [CrossRef] [PubMed]

44. Ma, X.; Zhang, C.; Kim, D.Y.; Huang, Y.; Chatt, E.; He, P.; Vierstra, R.D.; Shan, L. Ubiquitylome analysis reveals a central role for the ubiquitin-proteasome system in plant innate immunity. Plant Physiol. 2021, 185, 1943-1965. [CrossRef] [PubMed]

45. Yao, J.; Saenkham, P.; Levy, J.; Ibanez, F.; Noroy, C.; Mendoza, A.; Huot, O.; Meyer, D.F.; Tamborindeguy, C. Interactions "Candidatus Liberibacter solanacearum"-Bactericera cockerelli: Haplotype effect on vector fitness and gene expression analyses. Front. Cell. Infect. Microbiol. 2016, 6, 62. [CrossRef] [PubMed]

46. Lu, Q.; Tang, X.; Tian, G.; Wang, F.; Liu, K.; Nguyen, V.; Kohalmi, S.E.; Keller, W.A.; Tsang, E.W.T.; Harada, J.J.; et al. Arabidopsis homolog of the yeast TREX-2 mRNA export complex: Components and anchoring nucleoporin. Plant J. 2010, 61, 259-270. [CrossRef] [PubMed]

47. Wurch, T.; Lestienne, F.; Pauwels, P.J. A modified overlap extension PCR method to create chimeric genes in the absence of restriction enzymes. Biotechnol. Tech. 1998, 12, 653-657. [CrossRef]

48. AU-Fabrick, J.A.; AU-Hull, J.J. Transient expression and cellular localization of recombinant proteins in cultured insect cells. JoVE 2017, 122, e55756. [CrossRef]

49. Hink, W.F. Established insect cell line from the cabbage looper. Trichoplusia Nat. 1970, 226, 466-467. [CrossRef]

50. Van Eck, J.; Keen, P.; Tjahjadi, M. Agrobacterium tumefaciens-mediated transformation of Tomato BT. In Transgenic Plants: Methods and Protocols; Kumar, S., Barone, P., Smith, M., Eds.; Springer: New York, NY, USA, 2019; pp. 225-234. ISBN 978-1-4939-8778-8.

51. Chetty, V.J.; Ceballos, N.; Garcia, D.; Narváez-Vásquez, J.; Lopez, W.; Orozco-Cárdenas, M.L. Evaluation of four Agrobacterium tumefaciens strains for the genetic transformation of tomato (Solanum lycopersicum L.) cultivar Micro-Tom. Plant Cell Rep. 2013, 32, 239-247. [CrossRef] 